УДК 332.1:528.9: 004

$10.17213 / 2075-2067-2021-1-220-230$

\title{
АНАЛИЗ ИСПОЛЬЗОВАНИЯ ГИС В МУНИЦИПАЛЬНЫХ ОБРАЗОВАНИЯХ РОСТОВСКОЙ ОБЛАСТИ
}

\author{
(C) 2021 г. $\quad$ О. А. Ткачева, Е. П. Лукьянченко, Е. А. Лукьянченко
}

Новочеркасский инюенерно-мелиоративный институт имени А. К. Кортунова (филиал), Донской государственный аграрный университет, г. Новочеркасск, Россия

Целью исследования является анализ использования геоинформаџионных технологий муниципальных образований Ростовской области за период 2018-2020 г2. и предложение мероприятий по совершенствованию использования геоинформационных технологий.

Методологическую базу исследования представляют общенаучные методы логического и статистического анализа, а также элементы системного подхода.

Результаты исследования. Использование геоннформаџионных систем существенно влияет на разработку мероприятий, принятие решений, а также возможность создания документов нового поколения в сфере управления территориями муниципальных образований. Анализ использования геоинформачионных технологий в муниципальных образованиях Ростовской области позволил определить невысокую активность их использования, потребность в повышении циифровой квалификации всех категорий пользователей, отсутствие оперативности актуализации информационных ресурсов ГИС РО. Всё это говорит о необходимости выработки системы мер по активизации использования ГИС в муниципальных образованиях.

Перспективы исследования составляет обоснование необходимости активизации применения геоинформационной системы Ростовской области при разработке мероприятий устойчивого развития территорий муниџипальных образований.

Ключевые слова: геоинформационные технологии; геоинформаџионная система Ростовской области; территориальное планирование; устойчивое развитие; муниципальное образование.

\section{ANALYSIS OF GIS USE IN MUNICIPALITIES OF THE ROSTOV REGION}

\author{
(C) 2021 O. A. Tkacheva, E. P. Lukyanchenko, E. A. Lukyanchenko
}

\section{Novocherkassk Reclamation Engineering Institute named after A. K. Kortunov (branch), Donskoy State Agrarian University, Novocherkassk, Russia}

The purpose of the study is to analyze the use of geoinformation technologies in municipalities of the Rostov region for the period 2018-2020 and propose measures to improve the use of geoinformation technologies.

The methodological basis of the research is represented by General scientific methods of logical and statistical analysis, as well as elements of a systematic approach.

Research result. The use of geographic information systems significantly affects the development of measures, decision-making, as well as the possibility of creating a new generation of documents in the field of management of municipal territories. Analysis of the use of geoinformation 
technologies in the municipalities of the Rostov region allowed us to determine the low activity of their use, the need to improve the digital skills of all categories of users, and the lack of efficiency in updating GIS RO information resources. All this indicates the need to develop a system of measures to enhance the use of GIS in municipalities.

The research prospects are based on the need to activate the use of the geographic information system of the Rostov region in the development of measures for the sustainable development of municipal territories.

Key words: geoinformation technologies; geographic information system of the Rostov region; territorial planning; sustainable development; municipal formation.

Введение. В качестве условий устойчивого развития территорий муниципальных образований можно выделить территориальное планирование и градостроительное зонирование. Территориальное планирование в этом случае рассматривается как планирование пространственного развития муниципалитета в целях формирования комфортной среды проживания и ведения хозяйственной деятельности. Оно основывается на учёте пространственных территориальных закономерностей размещения, природных, социальных и экономических явлений и их взаимодействий. Документы территориального планирования позволяют «привязать» стратегические цели, программы, инвестиционные проекты к конкретной территории.

Современные подходы по территориальному планированию должны опираться на геоинформационные методы, т.е. подразумевается активное использование цифровых геопространственных данных. Для территориального планирования под геопространственными данными понимаем информацию, идентифицирующую географическое местоположение и свойства естественных или искусственно созданных объектов, а также их границ на земле. Геоинформационные методы могут быть эффективно использованы для всего ряда документации территориального планирования [1, 2, 3], а тенденции цифровой экономики обусловливают требование разработки документации по территориальному планированию в виде электронных (цифровых) карт. При этом составление карт должно выполняться в строгом соответствии с установленной системой классификации и кодирования информации территориального планирования.
В состав материалов по обоснованию схем и карт территориального планирования включается большое количество геопространственных данных. Большая часть информации может быть получена из открытых источников, в том числе и Федеральной государственной информационной системы территориального планирования [4] или геоинформационных систем муниципальных образований, поэтому считаем важным проанализировать уровень использования геоинформационных систем в муниципальных образованиях субъектов Российской Федерации. В нашем исследовании остановимся на геоинформационной системе Ростовской области (ГИС РО).

Обсуждение результатов исследования. Основной целью ГИС Ростовской области является создание условий, обеспечивающих доступ всех заинтересованных сторон к пространственным данным и их эффективное использование [5]. ГИС РО обеспечивает повышение качества и эффективности управленческих решений за счёт широкого использования информационных ресурсов пространственных данных (при разработке мероприятий по предотвращению и ликвидации негативных техногенных и природных процессов, повышения инвестиционной привлекательности Ростовской области, при совершенствовании механизмов рационального использования земель Ростовской области, при разработке документов территориального планирования и др.).

ГИС РО подразделяется на открытую и закрытую части, а её пространственные данные - на базовые и тематические данные (таблица 1). 
Векторная цифровая модель территории Ростовской области выступает в качестве базовой карты и охватывает территорию всей Ростовской области. Масштабы карт: на межселенную территорию - 1:100000, на застроенную территорию (55 муниципальных районов) - 1:5000; населённые пункты с численностью жителей свыше 1000 человек - 1:10000.

В целях оценки использования геоинформационных технологий в муниципальных образованиях Ростовской области была разработана методика расчёта показателя «Уровень использования геоинформационных технологий в муниципальном образовании» [6]. Оценка муниципальных образова- ний формируется на основании информации, содержащейся в ГИС РО по девяти показателям, которые можно сгруппировать в три блока:

- пользователь: количество сотрудников, зарегистрированных в ГИС РО, количество пользователей, активно использовавших возможности ГИС РО за отчётный период, количество сотрудников, прошедших обучение работе в ГИС РО и получивших документ о повышении квалификации в отчётном году;

- информационный ресурс: количество информационных ресурсов, размещённых в ГИС РО, количество информационных ресурсов, полностью заполненных обязательной информацией, количество информацион-

\section{Пространственные данные ГИС РО}

Таблица 1

\begin{tabular}{|c|c|}
\hline Слой & Содержание \\
\hline \multicolumn{2}{|r|}{ Базовые пространственные данные } \\
\hline Рельеф & $\begin{array}{l}\text { Слой, отображающий рельеф Ростовской области, соответствующий } \\
\text { представлению на топографических картах }\end{array}$ \\
\hline Гидрография & $\begin{array}{l}\text { Групповой слой представлен водными объектами (площадные, линейные, } \\
\text { точечные объекты), расположенными на территории Ростовской области }\end{array}$ \\
\hline $\begin{array}{l}\text { Населенные } \\
\text { пункты }\end{array}$ & $\begin{array}{l}\text { Слой представлен кварталами жилых и нежилых строений, строениями } \\
\text { и объектами социальной инфраструктуры населённого пункта, являющи- } \\
\text { мися ориентирами, а также адресными данными }\end{array}$ \\
\hline Дорожная сеть & $\begin{array}{l}\text { Групповой слой представлен дорожной сетью Ростовской области, вклю- } \\
\text { чает в себя отображение железных дорог, дорог общего пользования, } \\
\text { шоссейных и грунтовых дорог, просек, дорожных сооружений, в том чис- } \\
\text { ле мостов, путепроводов, насыпей }\end{array}$ \\
\hline $\begin{array}{l}\text { Растительный } \\
\text { покров и грунты }\end{array}$ & $\begin{array}{l}\text { Групповой слой представлен древесной, кустарниковой, травянистой } \\
\text { растительностью с выделением отдельных грунтов }\end{array}$ \\
\hline Границы & $\begin{array}{l}\text { Слой представлен границами субъекта Российской Федерации и муници- } \\
\text { пальных образований, расположенных на территории Ростовской области }\end{array}$ \\
\hline \multicolumn{2}{|r|}{ Тематические пространственные данные } \\
\hline & $\begin{array}{l}\text { Сведения об объектах недвижимого имущества и земельных участках, } \\
\text { находящихся в государственной собственности Ростовской области и } \\
\text { расположенных на территории Ростовской области }\end{array}$ \\
\hline & $\begin{array}{l}\text { Сведения о природных ресурсах (полезные ископаемые, породные отва- } \\
\text { лы (терриконы) и др.) }\end{array}$ \\
\hline & $\begin{array}{l}\text { Сведения об инвестиционных проектах и площадках на территории Рос- } \\
\text { товской области }\end{array}$ \\
\hline & $\begin{array}{l}\text { Сведения об объектах капитального строительства областного подчине- } \\
\text { ния, финансируемых за счёт средств областного бюджета в рамках госу- } \\
\text { дарственных программ Ростовской области }\end{array}$ \\
\hline
\end{tabular}


ных ресурсов, созданных в ГИС РО пользователями муниципального образования;

- сервис: использование ГИС РО в качестве локальной геоинформационной системы, количество новостных сообщений, размещённых в открытой части ГИС РО за отчётный период, проведение актуализации информационных ресурсов, размещённых в ГИС РО в отчётном периоде.

Каждый показатель оценивается в баллах. Максимальное количество баллов для оценки уровня использования геоинформационных технологий в муниципальном образовании - 50 (таблица 2).

Расчёт показателя и составление рейтинга муниципальных образований по нему выполняет сектор геоинформационных систем и использования результатов космической деятельности Министерства информационных технологий и связи Ростовской области. В таблице 3 приведен рейтинг муниципальных образований Ростовской области за 2018-2020 гг. [7].

По таблице 3 видно, что городские округа характеризуются более высоким уровнем использования геоинформационных технологий, чем сельские муниципальные образования. Так, г. Таганрог находится на уровне «отлично» на протяжении всего периода анализа, а уровень «неудовлетворительно» отмечается только 2 раза в одном городском округе (г. Батайск). В сельских муниципальных образованиях за период анализа «неудовлетворительный» уровень использования геоинформационных технологий встречается в 16 районах $(37 \%)$, а «отличный» уровень использования геоинформационных технологий - в шести районах (14\%). Характерно, что есть районы, в которых «неудовлетворительный» уровень использования геоинформационных технологий отмечается на протяжении длительного периода (Тарасовский, Мясниковский). Далее оценим по всем видам муниципальных образований уровень использования, для удобства анализа сгруппируем муниципальные образования (таблица 4).

Данные таблицы 4 показывают, что уровень использования геоинформационных технологий в основном находится на «хорошо» (60\% в 2018 г., 38\% в 2019 г., 36\% в 2020 г.) и «удовлетворительно» (33\% в 2018 г., 40\% в 2019 г. и $40 \%$ в 2020 г.). При этом можно увидеть, что количество муниципальных образований с уровнем «отлично» увеличивается по годам (рисунок 1) равномерно, с незначительными колебаниями.

Значительными колебаниями характеризуются изменения количества муниципальных образований с уровнем «неудовлетворительно». Максимальное значение приходится на первый квартал 2019 г., далее ситуация выравнивается, но не снижается на уровень первого квартала 2018 г. Конечно, нужно учитывать, что в анализ не попала информация по третьему и четвертому кварталу 2020 г., а также ситуацию с распространением коронавируса, поэтому однозначный вывод на текущий момент времени сделать не представляется возможным.

Детальное изучение всех показателей, формирующих уровень использования, показывает невысокую цифровую компетентность пользователей, невысокую заполненность информационных ресурсов ГИС РО, а также низкую активность использования геоинформационных технологий при принятии управленческих мер по устойчивому развитию территорий муниципальных образований.

Таблица 2

\section{Уровень использования геоинформационных технологий в муниципальном образовании}

\begin{tabular}{|l|c|c|}
\hline \multirow{2}{*}{ Количество баллов } & \multicolumn{2}{|c|}{ Оценка } \\
\cline { 2 - 3 } & качественная & количественная \\
\hline от 41 до 50 баллов & отлично & $9-10$ \\
\hline от 31 до 40 баллов & хорошо & $7-8$ \\
\hline от 21 до 30 баллов & удовлетворительно & $5-6$ \\
\hline 20 и менее & неудовлетворительно & $1-4$ \\
\hline
\end{tabular}




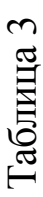

\begin{tabular}{|c|c|c|c|c|c|c|c|c|c|c|c|c|c|c|c|c|c|c|}
\hline \multirow{2}{*}{ 오 } & $\stackrel{\dot{\theta}}{\ominus}$ & $\frac{N}{m}$ & $\frac{9}{f}$ & $\frac{\infty}{n}$ & $\stackrel{\infty}{\stackrel{f}{f}}$ & $\frac{n}{2}$ & $\frac{n}{\sim}$ & $\frac{\hat{n}}{n}$ & $\frac{\infty}{b}$ & 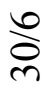 & $\stackrel{r}{\stackrel{f}{m}}$ & $\underset{m}{\stackrel{5}{*}}$ & $\frac{\hat{n}}{n}$ & $\stackrel{n}{\underset{d}{d}}$ & $\frac{b}{0}$ & $\frac{\infty}{2}$ & $\frac{+}{\infty}$ & 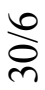 \\
\hline & $\dot{9}$ & $\frac{N}{m}$ & $\frac{a}{\sqrt[n]{\sigma}}$ & $\frac{\infty}{n}$ & $\frac{N}{n}$ & $\frac{n}{n}$ & $\frac{n}{n}$ & 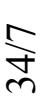 & $\underset{\infty}{\infty}$ & $\frac{0}{\sqrt{2}}$ & $\frac{0}{\infty}$ & $\underset{\mathrm{r}}{\stackrel{\mathrm{f}}{2}}$ & $\frac{N}{\sim}$ & $\frac{0}{\infty}$ & $\frac{n}{n}$ & $\stackrel{\infty}{a}$ & $\frac{n}{n}$ & $\frac{n}{m}$ \\
\hline & $\underset{2}{2}$ & $\frac{r}{m}$ & $\frac{\curvearrowright}{\stackrel{\vartheta}{\sigma}}$ & $\underset{m}{\infty}$ & $\stackrel{\infty}{\stackrel{f}{+}}$ & $\frac{b}{\sigma}$ & $\frac{n}{n}$ & $\underset{m}{\infty}$ & $\frac{n}{n}$ & $\frac{0}{\widehat{a}}$ & $\frac{0}{\widehat{a}}$ & $\frac{r}{n}$ & $\underset{\mathrm{r}}{\stackrel{5}{*}}$ & $\frac{n}{n}$ & $\stackrel{\infty}{a}$ & $\frac{\mathfrak{a}}{\stackrel{m}{\forall}}$ & $\frac{n}{n}$ & $\frac{n}{n}$ \\
\hline & $\begin{array}{l}\dot{\varphi} \\
\Xi\end{array}$ & $\frac{r}{n}$ & $\frac{\circ}{2}$ & $\frac{\sigma}{m}$ & $\frac{a}{n}$ & $\frac{\mathfrak{\infty}}{\stackrel{\infty}{N}}$ & $\frac{n}{\sim}$ & $\underset{m}{\infty}$ & $\frac{ \pm}{\sigma}$ & $\underset{\mathrm{m}}{\mathrm{J}}$ & $\frac{\infty}{\infty}$ & $\frac{\infty}{\infty}$ & $\stackrel{\curvearrowleft}{\curvearrowright}$ & $\underset{⿱}{ \pm}$ & $\frac{0}{0}$ & $\frac{a}{\stackrel{m}{\forall}}$ & $\frac{n}{\curvearrowright}$ & $\frac{n}{n}$ \\
\hline
\end{tabular}
응

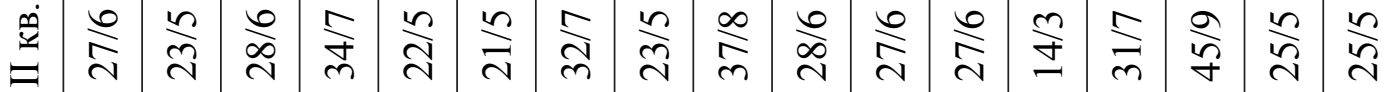

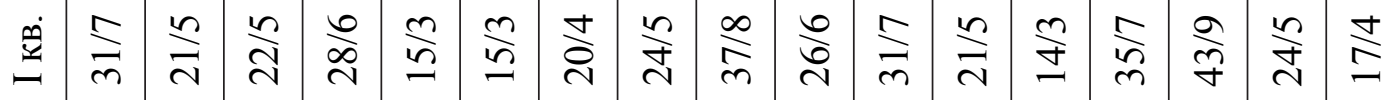

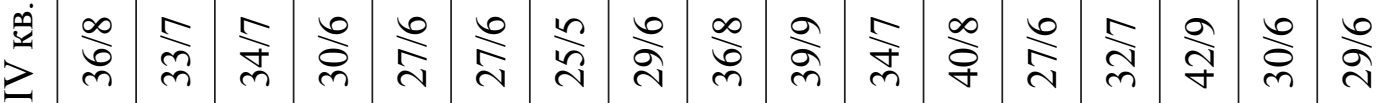
$\stackrel{\infty}{\mathrm{N}}$

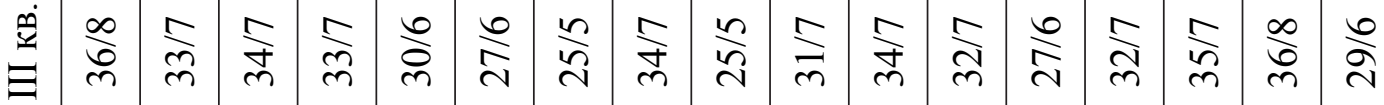

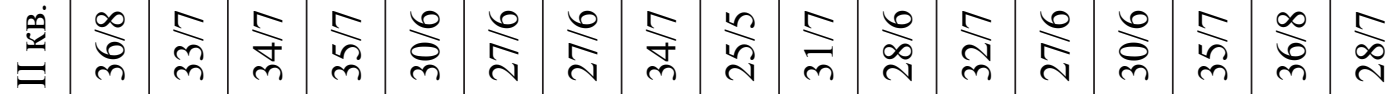

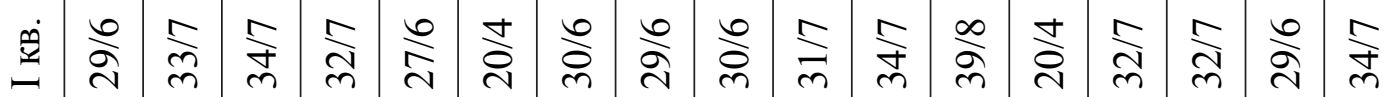

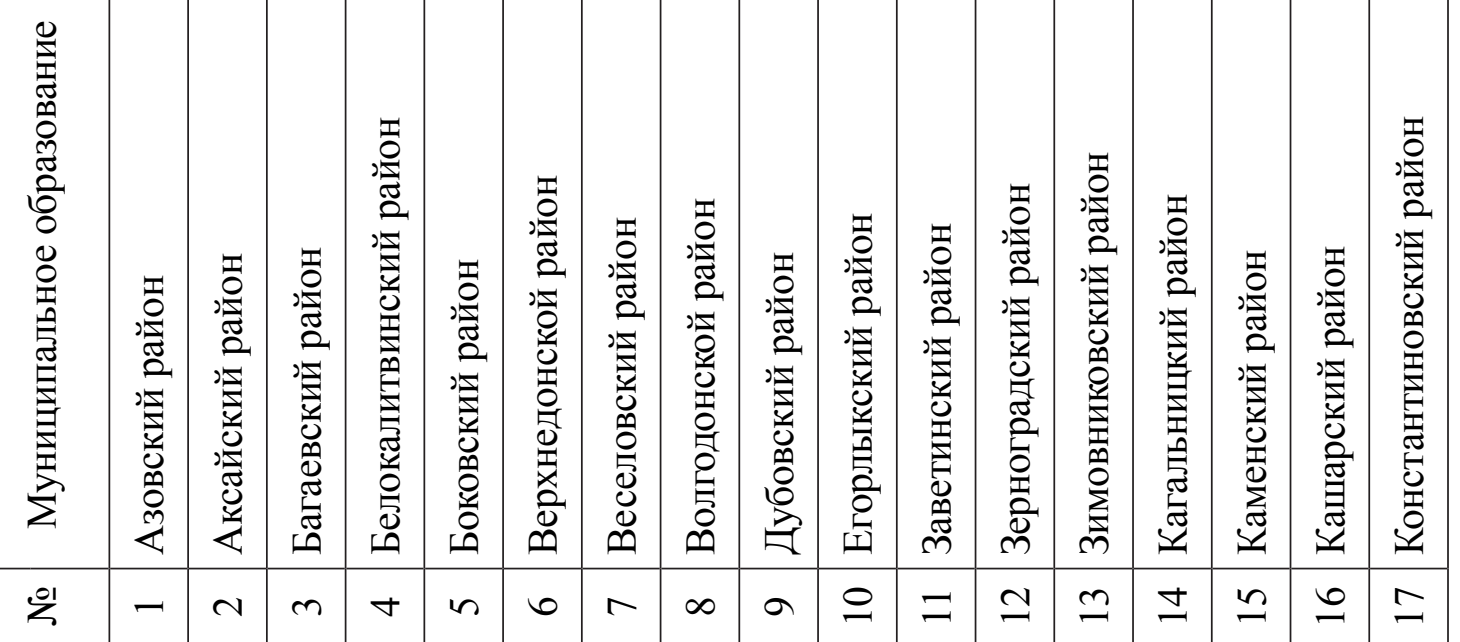




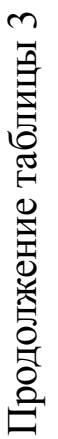

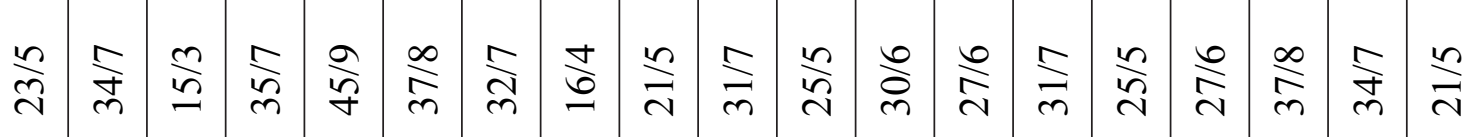

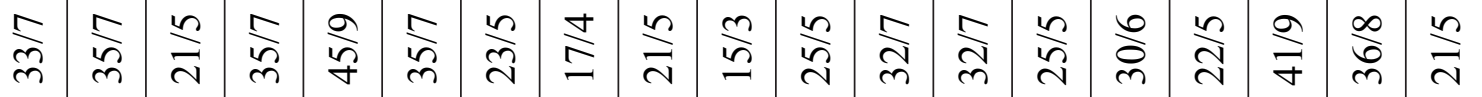

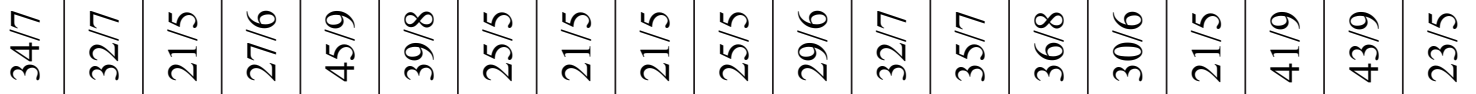

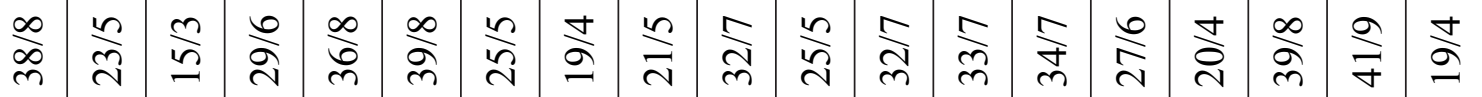

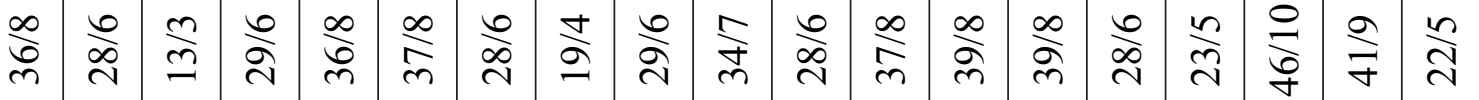

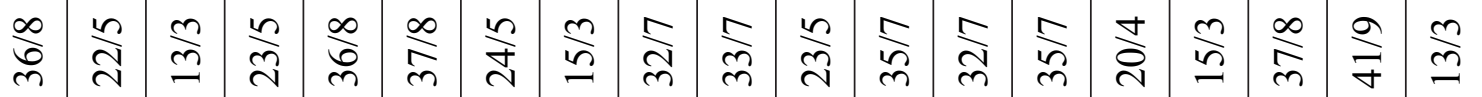

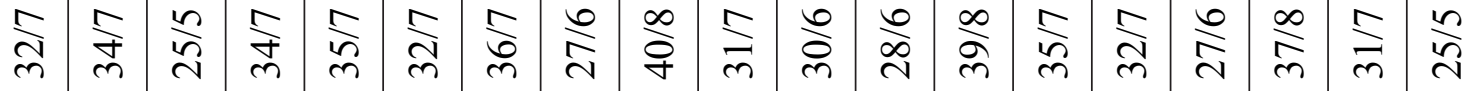

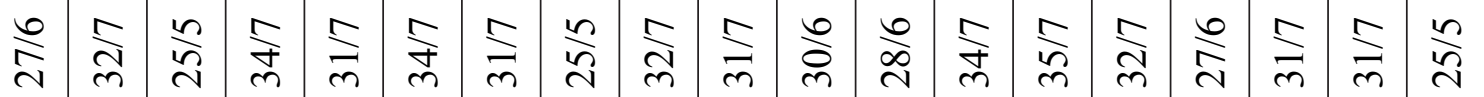

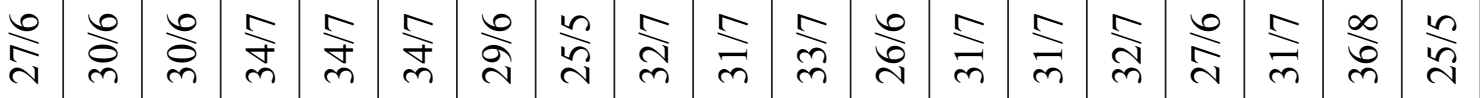

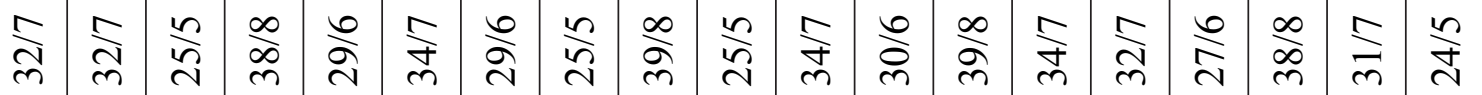

\begin{tabular}{|c|c|c|c|c|c|c|c|c|c|c|c|c|c|c|c|c|c|c|}
\hline & & & & & & & & & & & & & & & & & & \\
\hline 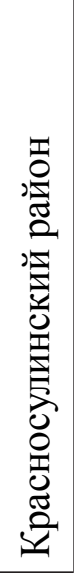 & 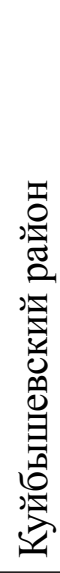 & 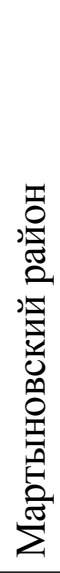 & 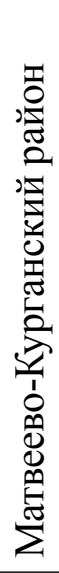 & 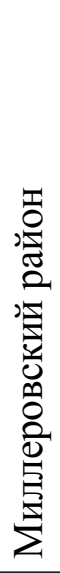 & 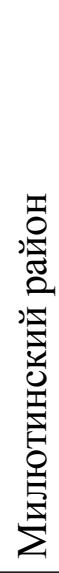 & 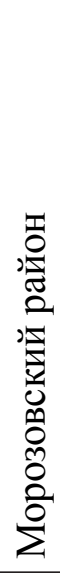 & 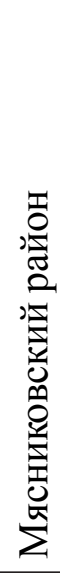 & 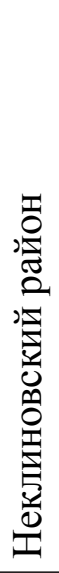 & 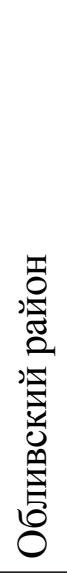 & 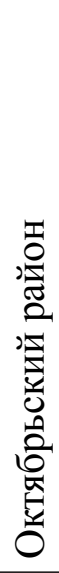 & 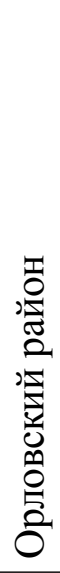 & 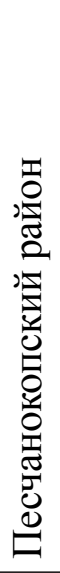 & 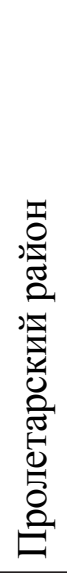 & 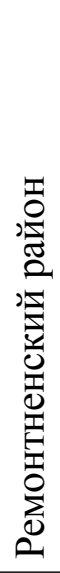 & 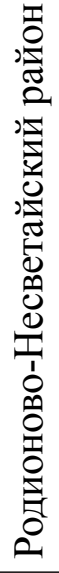 & 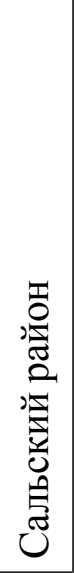 & 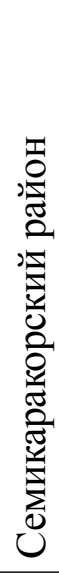 & 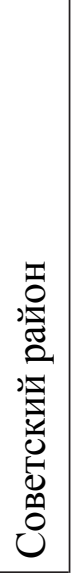 \\
\hline$\infty$ & 9 & $\stackrel{\Upsilon}{ }$ & $\vec{\sim}$ & ปี & 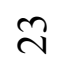 & $\stackrel{\nabla}{\sim}$ & $\stackrel{n}{\sim}$ & $\stackrel{\sim}{\sim}$ & $\hat{\sim}$ & $\stackrel{\infty}{\sim}$ & ते & 이 & $\bar{m}$ & ñ & $m$ & ষ & $\tilde{n}$ & ln \\
\hline
\end{tabular}


象

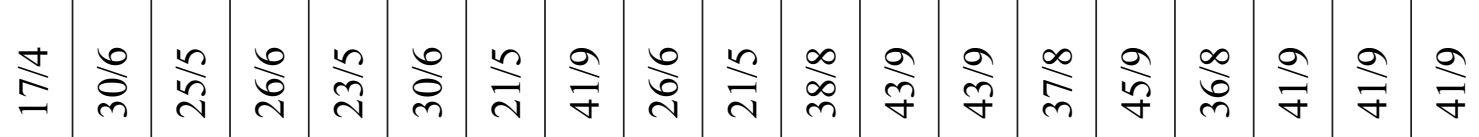

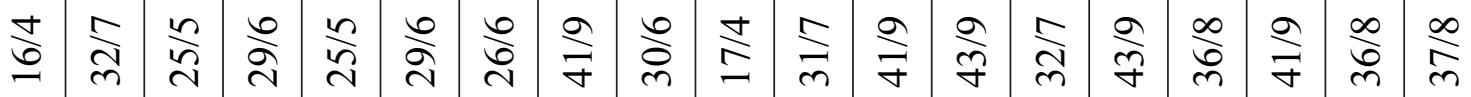

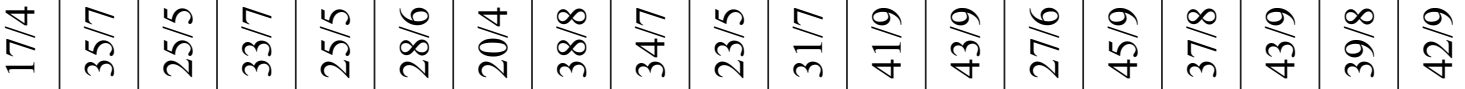

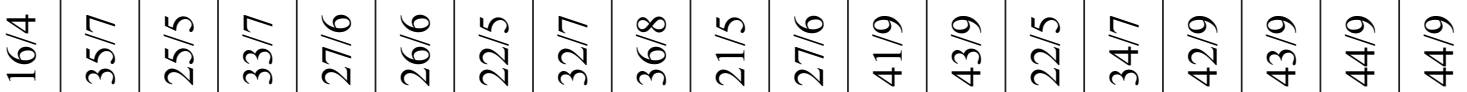

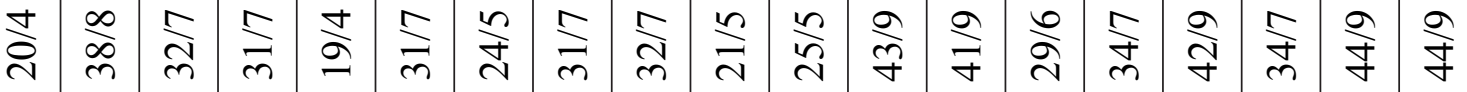

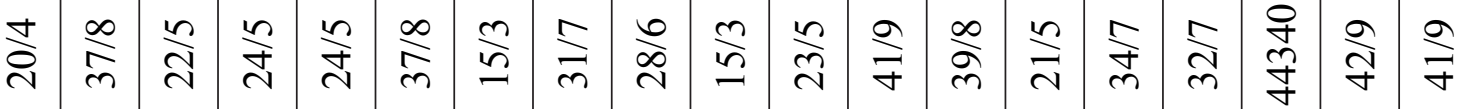

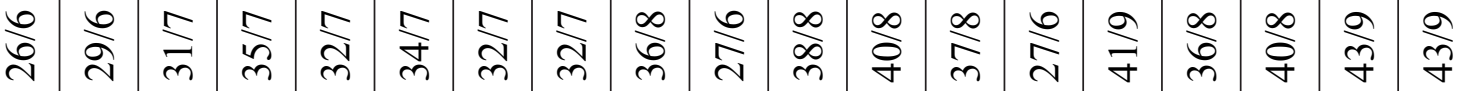

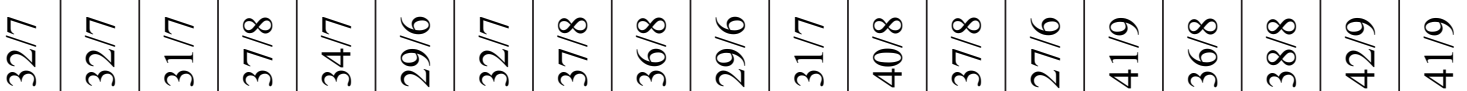

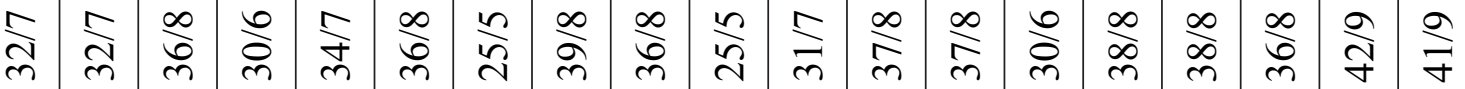

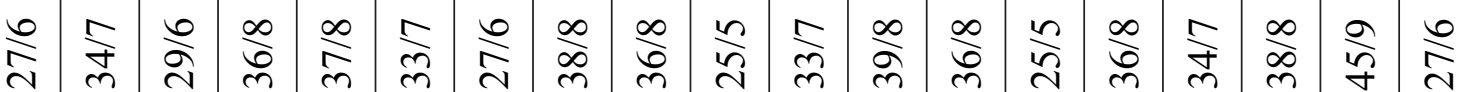

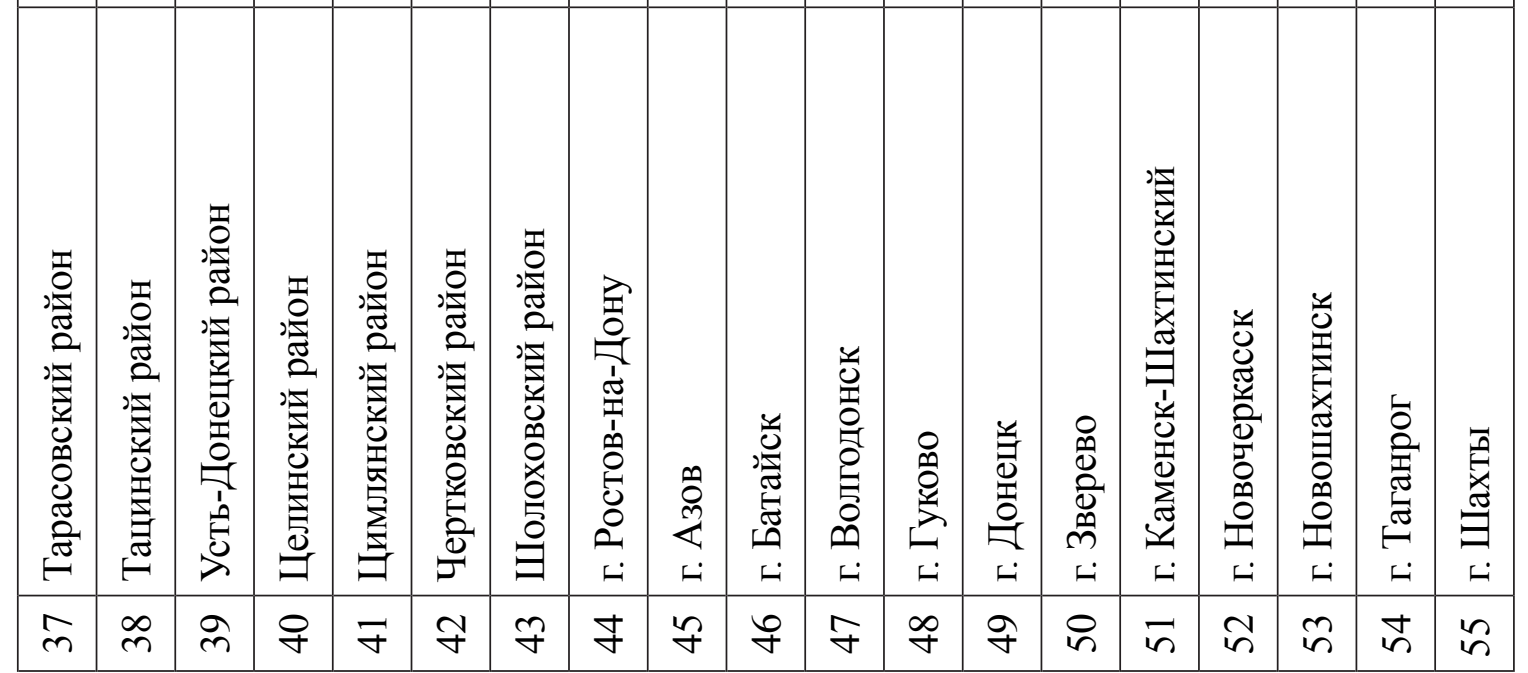


Группы муниципальных образований

по уровню использования геоинформационных технологий

\begin{tabular}{|c|c|c|c|c|c|c|c|c|c|c|}
\hline \multirow{2}{*}{$\begin{array}{c}\text { Уровень } \\
\text { использования }\end{array}$} & \multicolumn{4}{|c|}{2018} & \multicolumn{4}{|c|}{2019} & \multicolumn{2}{|c|}{2020} \\
\hline & І кв. & II кв. & III кв. & IV кв. & I кв. & II кв. & III кв. & IV кв. & I кв. & II кв. \\
\hline отлично & 1 & 2 & 3 & 4 & 5 & 8 & 9 & 10 & 8 & 9 \\
\hline хорошо & 32 & 33 & 36 & 33 & 19 & 19 & 19 & 21 & 22 & 20 \\
\hline удовлетворительно & 20 & 20 & 16 & 18 & 18 & 23 & 20 & 22 & 21 & 22 \\
\hline неудовлетворительно & 2 & 0 & 0 & 0 & 13 & 5 & 7 & 2 & 4 & 4 \\
\hline
\end{tabular}

40

35

30

25

20

15

10

5

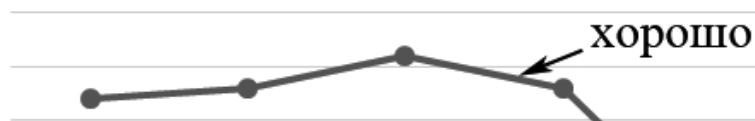
хорошо
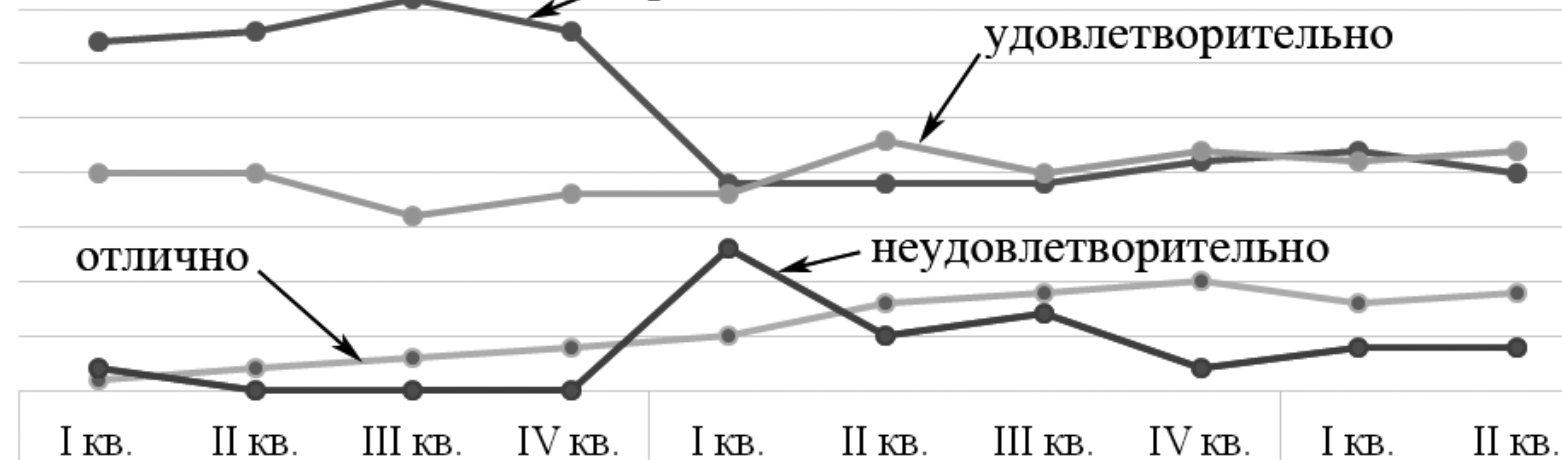

2018

Рис. 1. Динамика распределения муниципальных образований по уровню использованию геоинформационных технологий

Заключение. В целом результаты анализа говорят о необходимости обратить внимание на сельские муниципальные образования, проведение дополнительного подробного рассмотрения показателей неудовлетворительного использования геоинформационных технологий и выработки решения для повышения уровня их использования. Также важным и целесообразным считаем активизировать использование ГИС РО при разработке мероприятий и оформлении документов территориального планирования муниципальных образований.

\section{Литература}

1. Дышлюк С. С. Использование ГИС-технологий в процессе территориального планирования [Электронный ресурс] / С. С. Дышлюк, С.А. Сухорукова // Интерэкспо ГеоСибирь. - 2010. - №2. - Режим доступа: https://cyberleninka.ru/article/n/ispolzovaniegis-tehnologiy-v-protsesse-territorialnogoplanirovaniya (Дата обращения: 13.11.2020).

2. Красоэжвская О.В. Использование географических информационных систем в пространственном планировании и управлении территориями [Электронный ресурс]/ О.В. Красоэжвская, С.В. Скатерщиков // Вестник СПбГУ. Науки о Земле. - 2005. №3. - Режим доступа: https://cyberleninka. $\mathrm{ru} / \mathrm{article} / \mathrm{n} / \mathrm{ispolzovanie-geograficheskih-}$ informatsionnyh-sistem-v-prostranstvennomplanirovanii-i-upravlenii-territoriyami-1 (Дата обращения: 13.11.2020).

3. Барлиани И.Я. Возможности использования ГИС-технологий в системе планирования и управления территорией / И. Я. Барлиани // Интерэкспо Гео-Сибирь. - 2016. T. 6. - №1. - С. 247-250.

4. Федеральная государственная информационная система территориального 
планирования (ФГИС ТП) [Электронный pecypc]. - Режим доступа: https://fgistp. economy.gov.ru/.

5. Геоинформационная система Ростовской области. Министерство информационных технологий и связи Ростовской области [Электронный ресурс]. - Режим доступа: https://pd.gosreforma.ru/2019/05/08/rostov/.

6. Методика расчёта показателя «Уровень использования геоинформационных технологий в муниципальном образовании» [Электронный ресурс]. - Режим доступа: https:// docviewer.yandex.ru/view/429750970.

7. Уровень использования геоинформационных технологий в муниципальном образовании [Электронный ресурс]. - Режим доступа: http://special.minsvyaz.donland.ru/ Default.aspx?pageid $=153934$.

\section{References}

1. Dyshljuk S.S. Ispol'zovanie GIS-tehnologij $\mathrm{v}$ processe territorial'nogo planirovanija [The use of GIS technologies in the process of territorial planning] [Jelektronnyj resurs] / S. S. Dyshljuk, S.A. Suhorukova // Interjekspo Geo-Sibir'. — 2010. — №2. — URL: https:// cyberleninka.ru/article/n/ispolzovanie-gis-tehnologiy-v-protsesse-territorialnogo-planirovaniya (Date accessed: 13.11.2020).

2. Krasojezhvskaja O.V. Ispol'zovanie geograficheskih informacionnyh sistem $\mathrm{v}$ prostranstvennom planirovanii i upravlenii territorijami [The use of geographical information systems in spatial planning and management of territories] [Jelektronnyj resurs] / O.V. Krasojezhvskaja, S. V. Skatershhikov // Vestnik SPbGU. Nauki o Zemle [Vestnik SPbU. Earth Sciences]. 2005. - №3. - URL: https://cyberleninka. $\mathrm{ru} /$ article/n/ispolzovanie-geograficheskih-informatsionnyh-sistem-v-prostranstvennomplanirovanii-i-upravlenii-territoriyami-1 (Date accessed: 13.11.2020).

3. Barliani I. Ja. Vozmozhnosti ispol'zovanija GIS-tehnologij v sisteme planirovanija i upravlenija territoriej [The use of GIS-technologies in the system of planning and territory management] / I. Ja. Barliani // Interjekspo Geo-Sibir'. 2016. — Vol. 6. — №1. - Pp. 247-250.

4. Federal'naja gosudarstvennaja informacionnaja sistema territorial'nogo planirovanija (FGIS TP) [Federal state information system of territorial planning (FGIS TP)] [Jelektronnyj resurs]. - URL: https://fgistp.economy.gov.ru/.

5. Geoinformacionnaja sistema Rostovskoj oblasti. Ministerstvo informacionnyh tehnologij i svjazi Rostovskoj oblasti [Geoinformation system of the Rostov region. Ministry of Information Technologies and Communications of the Rostov region] [Jelektronnyj resurs]. - URL: https://pd.gosreforma.ru/2019/05/08/rostov/.

6. Metodika raschjota pokazatelja «Uroven' ispol'zovanija geoinformacionnyh tehnologij v municipal'nom obrazovanii» [Methodology for calculating the indicator «The level of use of geoinformation technologies in municipal education»] [Jelektronnyj resurs]. — URL: https:// docviewer.yandex.ru/view/429750970.

7. Uroven' ispol'zovanija geoinformacionnyh tehnologij $\mathrm{v}$ municipal'nom obrazovanii [The level of use of geoinformation technologies in municipal education] [Jelektronnyj resurs]. URL: http://special.minsvyaz.donland.ru/Default.aspx?pageid=153934. 

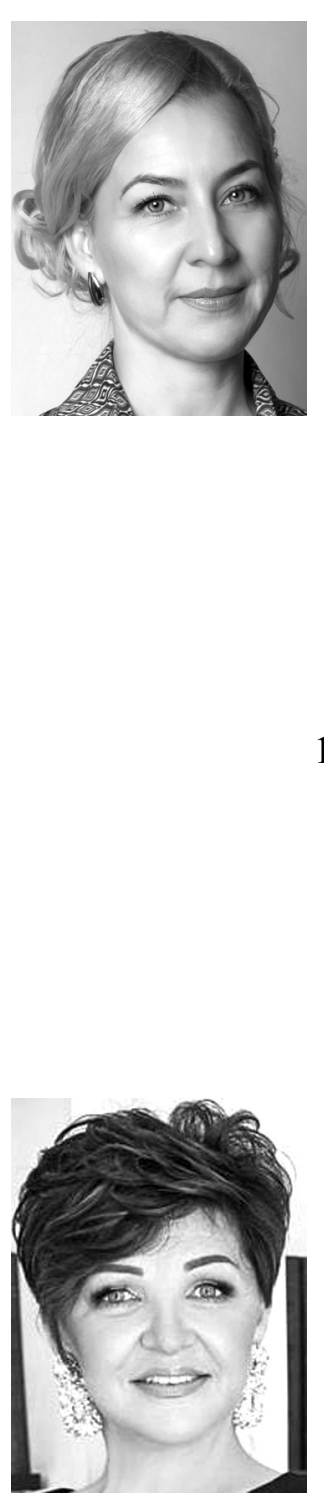

Ткачева Ольга Александровна - кандидат сельскохозяйственных наук, доцент кафедры «Кадастр и мониторинг земель» Новочеркасского инженерно-мелиоративного института им. А.К. Кортунова. Сферой научных интересов является информационное обеспечение и сопровождение мелиоративной, землеустроительной и кадастровой деятельности.

Tkacheva Olga Aleksandrovna - Candidate of Agricultural Sciences, Associate Professor, Department «Cadastre and Lands Monitoring», Novocherkassk Reclamation Engineering Institute named after A. K. Kortunov. Her research interests include information support and support of land reclamation, land management and cadastral activities.

346428, г. Новочеркасск, ул. Пушкинская, 111

111 Pushkinskaya st., 346428, Novocherkassk, Russia

E-mail: allesgut75@mail.ru

Лукьянченко Елена Павловна - кандидат экономических наук, доцент кафедры «Землепользование и землеустройство» Новочеркасского инженерно-мелиоративного института им. А.К. Кортунова. Сферой научных интересов является экономика и экология территориальных образований, рациональное природопользование.

Lukyanchenko Elena Pavlovna - Candidate of Economic Sciences, Associate Professor of the Department of Land Use and Land Management, Novocherkassk Reclamation Engineering Institute named after A. K. Kortunov. Her research interests include economics and ecology of territorial entities and rational use of natural resources.

346428, г. Новочеркасск, ул. Пушкинская, 111

111 Pushkinskaya st., 346428, Novocherkassk, Russia

E-mail:1407602@mail.ru 


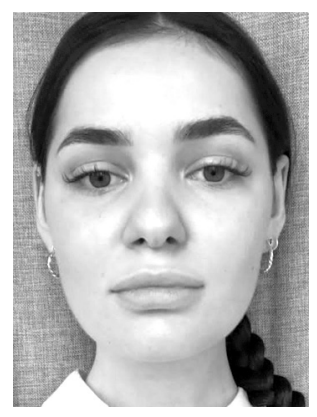

Лукьянченко Елизавета Андреевна - магистрант кафедры «Землепользование и землеустройство» Новочеркасского инженерно-мелиоративного института им. А. К. Кортунова. Сферой научных интересов является экономика и экология территориальных образований, территориальное планирование.

Lukyanchenko Elizaveta Andreevna - Master's student of the Department of Land Use and Land Management, Novocherkassk Reclamation Engineering Institute named after A. K. Kortunov. Her research interests include economics and ecology of territorial entities, and territorial planning.

346428, г. Новочеркасск, ул. Пушкинская, 111

111 Pushkinskaya st., 346428, Novocherkassk, Russia

E-mail:1407602@mail.ru 